DOI: $10.17805 /$ trudy.2017.1.7

пСИхологИя

\title{
СОВЛАДАЮЩЕЕ ПОВЕДЕНИЕ МАТЕРЕЙ, ВОСПИТЫВАЮЩИХ ДЕТЕЙ С ДИАГНОЗОМ ФЕНИЛКЕТОНУРИЯ
}

\author{
С. М. Буренина \\ Московский гуманитарный университет
}

\begin{abstract}
Аннотация: В статье рассматривается проблема изучения адаптивного потенцзиала матерей, имеющих детей, страдающих фенилкетонурией. Представлены данные сравнительного анализа копинг-стратегий и механизмов психологической защиты с контрольной группой женщин, воспитывающих здоровых детей.
\end{abstract}

Ключевые слова: адаптация; совладание; совладающее поведение; адаптационный потенциал; психологическая защита

\section{COPING BEHAVIOUR OF MOTHERS WITH CHILDREN DIAGNOSED WITH PHENYLKETONURIA (FELLING'S DISEASE)}

\author{
S. M. Burenina \\ Moscow University for the Humanities
}

\begin{abstract}
The article deals with the problem of studying the adaptive potential of mothers with children suffering from phenylketonuria. The article also presents data of the comparative analysis of coping strategies and psychological defence mechanisms with a control group of women raising healthy children.
\end{abstract} defence

Keywords: adaptation; coping; coping behavior; adaptability potential; psychological

В настоящее время в психологической науке активно развивается интерес к проблеме, получившей название «психологическое совладание». Современными исследователями отмечается необходимость дифференцированного подхода к изучению совладающего поведения, предполагающего учет специфики разных типов ситуаций (Суркова, Гребеникова, 2011; Суркова, Гурова, 2012; Суркова, 2011). Каждая психологическая ситуация представляет собой единство внешних условий и их внутренней субъективной интерпретации. Она содержит сложное сочетание намерений и притязаний субъекта, детерминируется его опытом и обращена в будущее предъявлением новых требований. Очевидно, что «трудность» ситуации в каждом конкретном случае будет определяться именно теми условиями, в рамках которых эта ситуация реально существует, а субъек- 
тивная оценка ее индивидом будет влиять на выбор стратегии совладающего поведения (Нартова-Бочавер, 1997).

В последние годы появились работы, свидетельствующие о необходимости активного изучения проблем семьи, воспитывающей ребенка с нарушениями и отклонениями в развитии. При этом внилмание уделяется не только вопросам абилитации, коррекции и социальной адаптации «особых» детей, но и психологическому состоянию их родителей и семьи в целом. Появление малыша с врожденными аномалиями нарушает весь обычный ход жизни семьи. Обнаружение у ребенка дефекта вызывает у родителей тяжелое стрессовое состояние, семья оказывается в трудной психологической ситуации. Все надежды, связанные с будущим ребенка, рушатся в один миг. Обретение новых жизненных ценностей и осмысление произошедшего затягивается иногда на длительный период. Некоторым из родителей нужны годы, чтобы прийти к принятию своего ребенка, другие - не достигают этого никогда. Это может быть обусловлено как психологическими особенностями личности родителей, так и диагнозом ребенка и степенью выраженности его аномалии, социальным окружением (Гуслова, Стуре, 2007).

Обычно затрагиваются две сферы жизни родителей. Во-первых, это практическое обеспечение и уход за ребенком, что нередко требует немалых финансовых затрат и ограничивает профессиональную деятельность и досуг. Во-вторых, неполноценность ребенка влияет на отношения между супругами, а также на отношения между родителями и их здоровыми детьми и на прочие социальные контакты (Цубер, Вейс, 2007).

Родители ребенка с аномалиями находятся под воздействием хронического стресса, хотя часто, на первый взгляд, кажутся вполне благополучными. Они отмечают возникновение у них чувства безнадежности, появляется дисгармония в супружеских отношениях. Страх за будущее ребенка, расте $\neg$ янность, незнание особенностей воспитания приводят к тому, что родители отгораживаются от близких, друзей и знакомых, предпочитая переносить свое горе в одиночку. Особенно уязвимыми оказываются матери, поскольку именно на них приходится основное давление семейного стресса. Оберегая других членов семьи, они сами часто оказываются в депрессивном состоянии. Им свойственно снижение психического тонуса, потеря вкуса к жизни. Из-за утраты перспектив профессиональной карьеры, невозможности реализовать свои планы снижается самооценка.

Согласно многочисленным исследованиям, появление в семье ребенка-инвалида можно отнести к классу ключевых жизненных событий, носящих психотравмирующий характер, требующих адаптации матери к сложившимся условиям существования с больным ребенком, которая во многом опирается на изменения в системе основных интересов, 
потребностей, склонностей, идеалов, устремлений, построения субъективной картины жизни. У матерей детей-инвалидов, как полагают некоторые авторы, актуализируется генетическая тревога, несущая серьезные ограничения в проявлении материнских способностей, признании своего ребенка, вызывая неадекватные стратегии совладания с ситуацией. Известно, что наибольшую опасность в плане негативного влияния на развитие ребенка оказывают уровень депрессивности, низкий локус контроля и психологические защиты, используемые взрослыми. Так, данные исследований по изучаемой проблеме показывают, что депрессивные матери с низким локусом контроля проявляют в парных взаимодействиях с ребенком более принудительный стиль, а самой неблагополучной для психического развития ребенка является используемая матерью психологическая защита - регрессия (Колпакова, 2006).

Говоря о совладающем поведении, мы полагаем, что главная задача копинга состоит в том, чтобы адаптировать человека к ситуации, позволяя ему овладеть ею, ослабить или смягчить ее стрессовое действие. Таким образом, мы придерживаемся точки зрения ряда авторов, которые считают, что данное понятие охватывает широкий спектр человеческой активности - от бессознательных психологических защит до целенаправленного преодоления кризисных ситуаций. В более широком смысле сюда включаются все виды взаимодействия человека с внешними и внутренними задачами - попытки овладеть или смягчить, привыкнуть или уклониться от требований проблемной ситуации.

Нами было проведено исследование совладающего поведения матерей, воспитывающих детей с диагнозом фенилкетонурия. Фенилкетонурия - это наследственное заболевание, обусловленное нарушением аминокислотного обмена, которое проявляется отставанием в физическом развитии и прогрессирующим слабоумием.

Данное эмпирическое исследование осуществлялось в двух группах: экспериментальной и контрольной.

Экспериментальную группу составили матери детей с фенилкетонурией в возрасте от 23 до 52 лет в количестве 36 человек; средний возраст 34,3 года. Количество детей у женщин - от 1 до 3, один ребенок имеет диагноз фенилкетонурия.

Контрольную группу составили матери условно здоровых детей (не страдающих врожденными аномалиями или приобретенными патологиями), в возрасте от 27 до 55 лет в количестве 38 человек, средний возраст - 34,4 года. Количество детей - от 1 до 3, все дети условно здоровы.

В исследовании приняли участие как работающие, так и неработающие женщины из полных и неполных семей. 
Итоги проделанной работы позволяют выделить несколько основных аспектов.

Первый касается ряда общих особенностей личности матерей больных детей. Анализ эмпирических данных, полученных при обследовании индивидуально-личностных характеристик женщин, имеющих больных детей, показал, что при наличии высоких показателей по всем личностным факторам значения привязанности и самоконтроля у них оказались достоверно ниже, чем у матерей здоровых детей.

Результаты изучения представлений матерей детей с фенилкетонурией об осмыслености своей жизни дают основание сделать заключение об общем снижении их смысложизненных ориентаций, они в меньшей степени ощущают себя хозяевами своей жизни.

Полученные результаты совпадают с данными исследования субъективных представлений о жизненных перспективах, проведенных на женщинах, имеющих детей-инвалидов, которые показали, что матери здоровых детей в своей субъективной картине большую важность в жизни придают временному интервалу «настоящее-будущее», а матери детейинвалидов - «прошлое-настоящее». Мысли о будущем здесь отходят на дальний план, что отражает существующие переживания и опасения по поводу предстоящих изменений, возможно, не в лучшую сторону в их жизни, и жизни их «особого ребенка» (Шмакова, 2008).

Второй аспект рассмотрения результатов исследования - анализ совладающего поведения матерей детей с фенилкетонурией. Матери детей с фенилкетонурией и матери здоровых детей применяют схожие стратегии для преодоления проблемных ситуаций. Женщинам обеих групп свойственны в качестве основных копинг-стратегий «планирование решения проблемы», «поиск социальной поддержки» и «положительная переоценка». Также матерями обеих групп активно используются стратегии «самоконтроль» и «принятие ответственности». Выявленные различия позволили констатировать большую выраженность стратегии «планирование решения проблем» у матерей больных детей.

Обращает на себя внимание тот факт, что значительно большее количество достоверных различий выявлено между экспериментальной и контрольной группами при анализе типов психологических защит. Так, если в экспериментальной группе основным механизмом защиты является отрицание, то матери контрольной группы чаще прибегают к такому механизму защиты, как интеллектуализация. Статистически значимые различия были выявлены при сравнении показателей общей напряженности психологических защит, а также для «отрицания», «регрессии», «проекции», «замещения» в сторону их увеличения для матерей детей с фенилкетонурией. 
Сходные результаты относительно преобладания таких типов защитных механизмов как «регрессия» и «отрицание» были получены в исследовании Л. М. Колпаковой, посвященной изучению совладающего поведения матерей детей с ДЦП (Колпакова, 2006). Автор полагает, что сверхнапряженное использование женщинами детей с ДЦП механизмов «отрицание» и «регрессия» отражают тенденцию активного исключения из сознания травмирующих фактов, связанных с ребенком, и недостаточного осознания своих и его проблем. Как известно, механизм «вытеснение» начинает функционировать в той фазе процесса удовлетворения потребностей, которая определяется как «борьба мотивов», но чаще всего в неосознаваемой форме. Мотив тревоги, обусловленный расхождением внутренних потребностей и ценностной системой личности, оказывается в данном случае сильнее. Механизм «проекция» может свидетельствовать о тенденции матерей больных детей снимать внутреннее напряжение и реализовывать свои потребности за счет приписывания собственных проблем внешним причинам и отреагирования вовне по внешнеобвиняющему типу.

Можно предположить, что различия в использовании совладающего поведения могут быть обусловлены глубокой травматизацией матерей, имеющих детей с фенилкетонурией, психопатогенным воздействием длительного стресса, связанного с болезнью ребенка, большими психическими затратами и внутренним напряжением. Хронический характер негативных переживаний, с ежедневными, не исчезающими трудностями обусловливает выраженность и иерархию защитных механизмов у матерей больных детей.

Таким образом, анализ совладающего поведения матерей детей с фенилкетонурией показал, что если на осознанном уровне эти механизмы практически такие же, как у матерей здоровых детей, то на бессознательном уровне они значительно разнятся. Т. е. согласно П. Крамеру, на осознанном уровне действия женщин, имеющих больного ребенка, также как и матерей здоровых детей управляются целью приближения к реальности, при этом на бессознательном уровне они не «проверяют» реальность, а изменяют свое состояние, чтобы уменьшить отрицательные эмоции. Другими словами для данного контингента женщин более свойственны, так называемые, эмоционально-ориентированные копинги. Их отличительной особенностью является то, что, с одной стороны, они включают моменты, связанные с избеганием или минимизацией проблемы, - уменьшение негативных эмоций. В этом случае к ним относятся классические защитные механизмы - отрицание, подавление, и др. С другой стороны, к ним относятся собственно копинг-стратегии, направленные на принятие проблемы и связанных с ней эмоций. (Гребенникова, Щербакова, 2012). 
Третий вывод, вытекающий из различного эмпирического материала, полученного в настоящем исследовании относится к анализу связей между личностными особенностями матерей детей с диагнозом фенилкетонурия и характером совладающего поведения. Результаты корреляционного анализа личностных факторов, а также смысложизненных ориентаций женщин обеих групп с копинг-стратегиями и психологическими защитами, позволили высказать предположение о том, что матери здоровых детей в случае трудной жизненной ситуации ищут опору во вне, тогда как матери больных детей - как во вне, так и внутри собственной личности.

Несмотря на очевидную остроту проблемы, она пока не находится в центре внимания психологической науки. В ее изучении преобладают психолого-педагогические и медико-психологические исследования, в которых основная роль отводится выявлению особенностей больных детей и не уделяется должного внимания здоровым членам семьи. На наш взгляд крайне важно сфокусировать внимание на окружении ребенка, так как психическое здоровье его родителей влияет не только на создание безопасной среды для реабилитации больного ребенка, но и на все жизненные перспективы семьи в целом. При этом необходимо учитывать специфичность ситуации: диагноз ребенка, прогноз и перспективы развития, индивидуальные особенности членов семьи, стадии проживания и переживания травмирующих событий.

\section{СПИСОК ЛИТЕРАТУРЫ}

Гребенникова, Н. В., Щербакова, Е. А. (2012) Особенности детскородительских отношений в семьях, воспитывающих детей с синдромом Дауна // Современная российская семья: прошлое, настоящее, будущее. Муром ; М. : Московский психолого-социальный университет. С. 40-46.

Гуслова, М. Н., Стуре, Т. К. (2007) Психологическое изучение матерей, воспитывающих детей-инвалидов // Психология семьи и больной ребенок : учебное пособие, хрестоматия. СПб. : Речь. С. 74-79.

Колпакова, Л. М. (2006) Механизмы психологической защиты и стратегии совладания со стрессом матерей, имеющих детей, страдающих церебральным параличом // Бюллетень сибирской медицины. № 2. С. 107-113.

Нартова-Бочавер, С. К. (1997) “Coping Behavior” в системе понятий психологии личности // Психологический журнал. Т. 18. № 5. С. 20-30.

Суркова, Е. Г. (2011) Творческая парадигма совладания с трудными жизненными ситуациями // Знание. Понимание. Умение. № 2. С. 222-228.

Суркова, Е. Г., Гребенникова, Н. В. (2011) Адаптация к повседневным перегрузкам у младших школьников // Вестник РУДН. № 2. С. 39-47. 
Суркова, Е. Г., Гурова Е. В. (2012) Глубина внутриличностного конфликта и зрелость совладающего поведения личности // Знание. Понимание. Умение. № 3. С. 251-256.

Цубер, Й., Вейс, Й. (2007) Трудности, возникающие у семей с неполноценными детьми // Психология семьи и больной ребенок : учебное пособие, хрестоматия. СПб. : Речь. С. 53-54.

Шмакова, С. С. (2008) Особенности временной трансспективы матерей детей-инвалидов : дисс. ... канд. психол. наук. Барнаул.

Дата поступления: 02.12.2016 г.

Буренина Светлана Михайловна - магистрант факультета психологии, педагогики и социологии Московского гуманитарного университета. Адрес: 111395, Россия, г. Москва, ул. Юности, д. 5. Тел.: +7 (499) 374-67-20. Эл. адрес: burenkindom@gmail.com. Научный руководитель - канд. псих. наук, проф. Н. В. Гребенникова.

Burenina Svetlana Mikhailovna, Graduate Student, Faculty of Psychology, Pedagogy and Sociology, Moscow University for the Humanities. Postal address: 5, Yunosti St., Moscow, Russian Federation 111395. Tel.: +7 (499) 374-67-20. Scientific Adviser - N. V. Grebennikova, Candidate of Psychology, Professor.

\section{Для циитирования:}

Буренина С. М. Совладающее поведение матерей, воспитывающих детей с диагнозом фенилкетонурия [Электронный ресурс] // Научные труды Московского гуманитарного университета. 2017, № 1.URL: http://journals.mosgu.ru/trudy/article/view/398 (дата обращения: дд.мм.гг.). DOI: 10.17805/trudy.2017.1.7 